COVID-19

\title{
Impact of COVID-19 pandemic on Italian Otolaryngology Units: a nationwide study
}

\section{Impatto della pandemia COVID-19 sulle Unità Operative di Otorinolaringoiatria in Italia: uno studio nazionale}

\author{
Giuditta Mannelli ${ }^{1,2}$, Massimo Ralli ${ }^{1,3}$, Marco Bonali ${ }^{1,4}$, Pasquale Capasso ${ }^{1,5}$, Pierre Guarino ${ }^{1,6}$, Valeria lannini ${ }^{1,7}$, \\ Niccolò Mevio ${ }^{1,8}$, Gennaro Russo ${ }^{1,5}$, Alfonso Scarpa ${ }^{1,9}$, Giacomo Spinato ${ }^{1,10}$, Davide Topazio ${ }^{1,11}$, Gabriele Molteni ${ }^{1,12}$ \\ ${ }^{1}$ COVID-19 Task Force of the Young Otolaryngologists of the Italian Society of Otolaryngology Head and Neck Surgery; \\ ${ }^{2}$ Head and Neck Oncology and Robotic Surgery, Department of Experimental and Clinical Medicine, University of Florence, Italy; \\ ${ }^{3}$ Department of Sense Organs, Sapienza University of Rome, Italy; ${ }^{4}$ Otolaryngology Head and Neck Surgery Department, University of \\ Modena, Italy; ${ }^{5}$ Otolaryngology, Head and Neck Surgery Unit AO dei Colli, Monaldi Hospital, Napoli, Italy; ${ }^{6}$ Otorhinolaryngology, Head \\ and Neck Surgery Unit "Santo Spirito" Hospital of Pescara, Italy; ${ }^{7}$ Otolaryngology Department, Dipartimento Strutturale Ospedaliero \\ Chirurgico di Rovigo ULSS 5, Rovigo, Italy; ${ }^{8}$ Department of Otolaryngology Niguarda Hospital, Milano, Italy; ${ }^{9}$ Department of Medicine \\ and Surgery, University of Salerno, Italy; ${ }^{10}$ Department of Neurosciences, Section of Otolaryngology and Regional Centre for Head \\ and Neck Cancer, University of Padova, Treviso, Italy - Department of Surgery, Oncology and Gastroenterology, Section of Oncology \\ and Immunology, University of Padova, Italy; ${ }^{11}$ Otolaryngology Department, Ospedale Mazzini, Teramo, Italy; ${ }^{12}$ Otolaryngology, Head \\ and Neck Surgery Unit, University Hospital of Verona Borgo Trento, Department of Surgery, Dentistry, Paediatrics and Gynaecology, \\ University of Verona, Italy
}

\section{SUMMARY}

Objective. The aim of this study was to provide an accurate picture of the changes which have occurred during the COVID-19 pandemic, and the contributions given by Italian Otolaryngology Units.

Methods. A 29-item questionnaire was completed and returned by 154 Otorhinolaryngology Units across Italy that investigated geographic distribution, the main changes which occurred in workload management and in clinical and surgical activities and screening procedures for COVID-19 in healthcare personnel and patients.

Results. Nearly half of the Otolaryngology Units that responded to the questionnaire were merged with other units, while $22 \%$ were converted into COVID-19 units or temporarily closed. A reduction of $8.55 \%$ in the number of team members was reported, and about $50 \%$ of the units applied uniform work shifts for all staff. Elective activities were uniformly stopped or delayed, passing from 30,295 (pre-COVID data) to 5,684 (COVID data) weekly procedures, with a mean decrease of $81.24 \%(\mathrm{p}<0.001)$.

Conclusions. Most of the elective otolaryngology activities were suspended during the pandemic; the only procedures were for oncology and emergency patients. Italian Otolaryngologists have demonstrated a high availability to collaborate with non-surgical colleagues.

KEY WORDS: COVID-19, otolaryngology, SARS-CoV-2, pandemic

\section{RIASSUNTO}

Obiettivo. Fornire un quadro accurato dei cambiamenti che si sono verificati e dei contributi forniti dalle Unità di Otorinolaringoiatria italiane durante la pandemia COVID-19. Metodi. Un questionario di 29 domande è stato completato da 154 unità. Sono stati investigati la distribuzione geografica del loro coinvolgimento, $i$ cambiamenti di gestione del carico di lavoro e delle attività clinico-chirurgiche e le procedure di screening applicate su personale sanitario e pazienti.

Risultati. Quasi la metà delle Unità che hanno risposto sono state fuse con altre unità operative, mentre il $22 \%$ è stato convertito in unità COVID-19 o temporaneamente chiuso. È stata segnalata una riduzione dell'8,55\% nel numero dei membri del gruppo di lavoro e circa il $50 \%$ dei dipartimenti ha applicato turni di lavoro per tutto il personale. Tutte le attività elettive sono state uniformemente interrotte o ritardate, passando da 30.295 (dati pre-COVID) a 5.684 (dati COVID) procedure settimanali, con una diminuzione media dell' $81,24 \%(p<0,001)$.
Received: May 7, 2020

Accepted: May 21, 2020

Published online: September 24, 2020

\section{Correspondence}

Giuditta Mannelli

Head and Neck Oncology and Robotic Surgery, Department of Experimental and Clinical Medicine, University of Florence, largo Brambillla 3,

50134 Florence, Italy

Tel. +39055 7945489

E-mail: mannelli.giuditta@gmail.com

Funding

None.

Conflict of interest

The Authors declare no conflict of interest.

How to cite this article: Mannelli G, Ralli M, Bonali M, et al. Impact of COVID-19 pandemic on Italian Otolaryngology Units: a nationwide study. Acta Otorhinolaryngol Ital 2020;40:325-331. https://doi.org/10.14639/0392-100X-N0832

() Società Italiana di Otorinolaringoiatria e Chirurgia Cervico-Facciale

\section{(c) (1) $(9)$}

This is an open access article distributed in accordance with the CC-BY-NC-ND (Creative Commons Attribution-NonCommercial-NoDerivatives 4.0 International) license. The article can be used by giving appropriate credit and mentioning the license, but only for non-commercial purposes and only in the original version. For further information: https:// creativecommons.org/licenses/by-nc-nd/4.0/deed.en 
Conclusioni. La maggior parte delle attività elettive in otorinolaringoiatria, a parte le procedure oncologiche e di emergenza, sono state sospese. Gli otorinolaringoiatri italiani hanno dimostrato un'alta disponibilità a collaborare con i reparti di medicina.

PAROLE CHIAVE: COVID-19, otolaringoiatria, SARS-CoV-2, pandemia

\section{Introduction}

The ongoing pandemic of Severe Acute Respiratory Syndrome CoronaVirus-2 (SARS-CoV-2) infection, also known as COVID-19, has spread rapidly worldwide since the first cases in Wuhan, China ${ }^{1}$. The first cases in Italy were diagnosed in Rome on January 29, 2020, when two Chinese tourists tested positive for the virus and were hospitalised and isolated at Spallanzani Hospital. On January $31^{\text {st }}$, the Italian government declared a national emergency.

Since the first case of an Italian patient affected by COVID-19 in the town of Lodi, Lombardy, the number of patients and related deaths in Italy progressively increased ${ }^{2}$. In fact, despite attempts to limit the outbreak at the primary cluster of infections by quarantining citizens and isolating the area, similar cases were progressively diagnosed in other cities and neighboring regions, such as Veneto and EmiliaRomagna, without evidence of any epidemiologic correlation to the first case. Since then, the COVID-19 infection spread across the country despite the containment measures applied by the Italian government, making Italy one of the worst hit countries with more than 214,457 confirmed cases and 29,684 deaths reported as of May 7, $2020^{3}$. On March 11, 2020, the Director-General of the World Health Organization (WHO) declared COVID-19 a pandemic ${ }^{4}$.

In the last two months, the Italian National Healthcare System has undergone multiple changes to face the pandemic, with closure or conversion of many units and hospitals into units solely dedicated to the treatment of COVID-19 patients ${ }^{5}$. Most elective outpatient clinical and surgical procedures were delayed or suspended, allowing the confluence of most of the resources towards Emergency Departments, Infectious Diseases Units, Respiratory Disease Units and Intensive Care Units (ICUs) ${ }^{6,7}$.

In this setting, although Otolaryngology-Head and Neck surgeons were not in the frontline of action, they were asked to contribute in managing patients with upper airway impairment, provide basic assistance, perform screening procedures (i.e. upper airway swab) and perform temporary tracheotomies in ICUs. This new arrangement implied a significant change in otolaryngology activities across the country ${ }^{8}$.

The aim of this nationwide study, in accordance with the Italian Society of Otolaryngology Head and Neck Surgery (SIOeChCF), was to provide a picture of the changes and contributions of otolaryngologist specialists during the COVID-19 pandemic over the last 2 months through a questionnaire administered to Italian Otolaryngology Units.

\section{Materials and methods}

This study was performed by the COVID-19 Task Force of the Italian Young Otorhinolaryngologists (GOS). On April 16, 2020, a 29-item questionnaire was sent by e-mail to all Otolaryngology Units in Italy $(\mathrm{n}=296)$; each unit was asked to respond within 4 days and the final compilation deadline was set as April 22, 2020. Data were subsequently collected and compiled anonymously in a unified dataset. Duplicates, when present, were removed.

The questionnaire investigated three major aspects of Italian Otolaryngology Units during the pandemic:

1. the geographic distribution of respondent units;

2. the main changes in workload management and distribution in terms of outpatient and inpatient procedure volumes;

3. COVID-19 screening procedures for patients and healthcare workers.

According to the Italian Instituto Superiore di Sanità (ISS) data ${ }^{9}$, Italian regions were divided into five zones based on the total number of cases as follows: 1) >20,000 (Lombardia, Emilia-Romagna); 2) 10,000-20,000 (Piemonte, Veneto); 3) 3,000-10,000 (Toscana, Marche, Lazio, Provincia Autonoma di Trento, Campania, Puglia, Liguria); 4) 1,0003,000 (Abruzzo, Friuli Venezia Giulia, Umbria, Provincia Autonoma di Bolzano, Sicilia, Valle D’Aosta, Sardegna); 5) $<$ 1,000 (Molise, Calabria, Basilicata).

\section{Statistical analysis}

Descriptive analysis was used to define the main clinical and demographic characteristics based on the responses to the questionnaire. Unpaired $\mathrm{T}$ test was used to evaluate differences for numeric values. A p-value less than 0.05 was considered the cutoff for statistical significance. Prism Software version 8.3.1 (GraphPad Software LLC) was used to perform statistical analysis.

\section{Results}

One-hundred fifty-four Otolaryngology Units (52\%) completed the questionnaire; $134(87 \%)$ units were public and $20(13 \%)$ were private and/or affiliated health facilities. 
Geographic distribution of respondent Italian

Otolaryngology Units

Lombardy represented the region with the highest number of Otolaryngology Units that replied to the questionnaire, while the lowest response rates were registered in Trentino Alto Adige, Valle d'Aosta and Molise. Figure 1 reports the geographic distribution of respondent units. Figure 2 shows the division of zones and the number of responses received from each zone. Thirty-eight responses were received from units in zone 1,27 from units in zone 2, 60 from zone 3,21 from zone 4 and 8 from units in zone 5 .

Based on the responses received, the majority of units

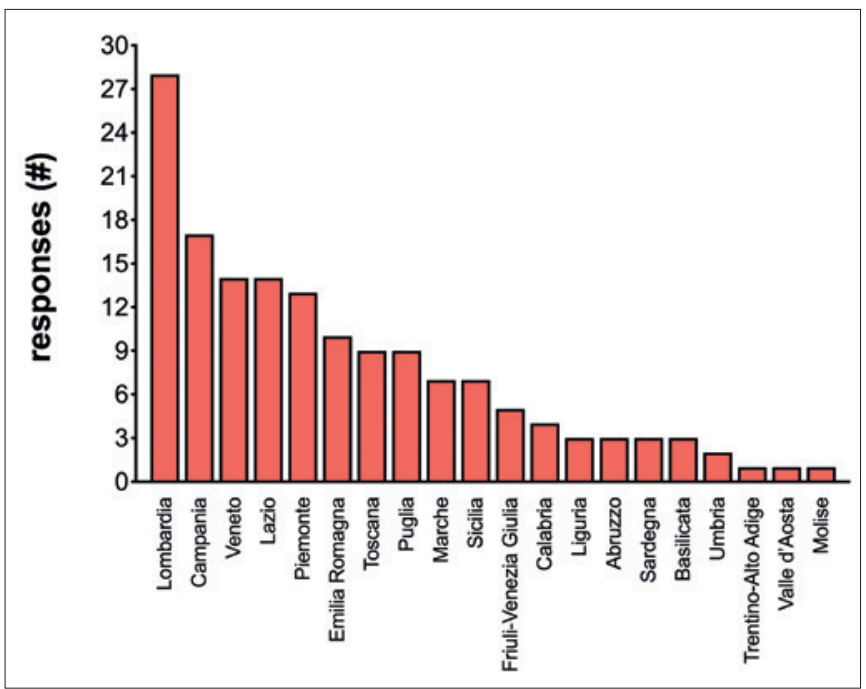

Figure 1. Representation of the response rate to our questionnaire sorted by region. The total number of responses is reported on the abscissa axis, while the ordinate axis indicates the 20 Italian regions.

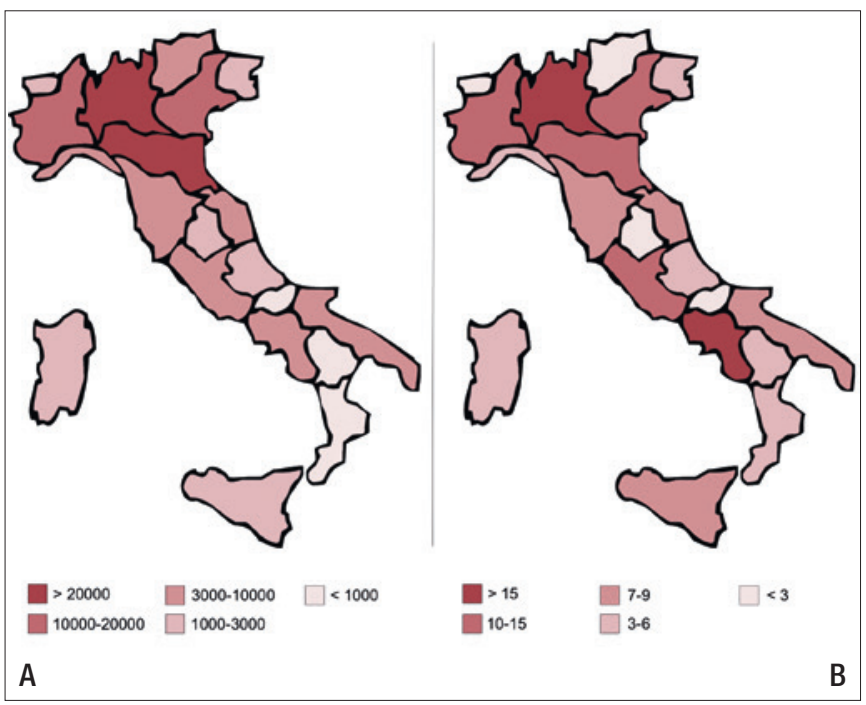

Figure 2. Graphical representation of (A) the distribution of COVID-19 positive cases in Italian regions (ISS, April 16, 2020); and (B) the response rate to our questionnaire sorted by the five zones identified according to the total number of cases.
(45.5\%) were merged with other units, and $10.4 \%$ were temporarily closed. Interestingly, no changes were reported by $10.4 \%$ of the units, while $11.6 \%$ were converted into COVID-19 wards. A significant reduction in hospital beds was reported by the remaining units $(22.1 \%)$. Table I summarises the activity changes sorted by zone.

A reduction in the number of team members was reported, and its percentage change during the pandemic was compared to the pre-COVID-19 setting. A decrease of $6.07 \%$ was recorded in the total number of otolaryngology specialists belonging to the 154 units, which declared a pre-COVID staff number of 1,136 specialists which was reduced to 1,067 during the state of emergency. The difference was not statistically significant $(p=0.364)$. In addition, the number of residents on duty was reduced from 465 to 397 (percentage reduction: $14.6 \% ; \mathrm{p}=0.054$ ). The reduction in each unit was proportional to work shift changes applied by each zone (Tab. II).

Interestingly, nearly 70\% (107/154) of the respondents declared a reallocation of staff members to Internal Medicine COVID-19 Units (52/107 - 48.6\%), emergency departments (20/107 - 18.7\%), ICUs (9/107 - 8.4\%), respiratory disease units $(7 / 107-6.5 \%)$, other services (7/107 - 6.5\%), Internal Medicine non-COVID-19 Units (5/107 - 4.7\%), infectious disease wards (5/107 - 4.7\%) and basic assistance services (2/107 - 1.9\%) (Fig. 3).

The highest percentage of reallocated colleagues was present in zone $1(46.7 \%)$, and these showed a progressive reduction passing from $20.5 \%$ in zone 2 and $23.4 \%$ in zone 3 , to less than $10 \%$ in zones 4 and 5 (6.5\% and $2.9 \%$, respectively).

In this setting, $48 \%$ and $50 \%$ of reallocation changes to Internal Medicine COVID-19 Units and Emergency Departments, respectively, occurred in zone 1, while units in zone 2 reported the majority of reallocations to Internal Medicine non-COVID-19 Units (Tab. III).

\section{Main changes in workload management and distribution in terms of outpatient and inpatient procedure volumes}

The questionnaire results showed a significant decrease in otolaryngology activities across the country during the pandemic with no substantial differences among the five zones. Outpatient visits showed a significant decrease in number of procedures per week $(80.54 \%$; $p<0.0001)$, passing from a pool of 26,035 evaluations usually performed during the pre-COVID-19 period to 5,067 registered outpatient procedures during the COVID-19 pandemic. A similar reduction $(89.91 \% ; \mathrm{p}<0.0001)$ was recorded for outpatient surgical procedures (i.e. surgical procedures under local anaesthesia) and for inpatient surgical procedures that decreased from 2,823/week to 472/week, a reduction of $83.28 \%(\mathrm{p}<0.0001)$. A detailed summary 
Table I. Activity changes in Otolaryngology Units sorted by zone.

\begin{tabular}{|c|c|c|c|c|c|c|}
\hline \multirow[t]{2}{*}{ Zone } & \multicolumn{5}{|c|}{ Changes in clinical practice in the 154 units } & \multirow[t]{2}{*}{ Total } \\
\hline & No change & Reduction in beds & Merged with other units & Converted into COVID-wards & Temporarily closed & \\
\hline 1 & 1 & 5 & 17 & 10 & 5 & $38(24.7 \%)$ \\
\hline 2 & 4 & 9 & 9 & 4 & 1 & $27(17.5 \%)$ \\
\hline 3 & 6 & 16 & 29 & 3 & 6 & $60(39 \%)$ \\
\hline 4 & 5 & 3 & 10 & 1 & 2 & $21(13.6 \%)$ \\
\hline 5 & 0 & 1 & 5 & 0 & 2 & $8(5.2 \%)$ \\
\hline Total & $16(10.4 \%)$ & $34(22.1 \%)$ & $70(45.5 \%)$ & $18(11.6 \%)$ & $16(10.4 \%)$ & $154(100 \%)$ \\
\hline
\end{tabular}

Table II. Number of staff members sorted by zone and work shift changes.

\begin{tabular}{|c|c|c|c|c|c|c|c|c|c|}
\hline \multirow[t]{2}{*}{ Zone } & \multicolumn{4}{|c|}{ Number of specialists and residents } & \multicolumn{5}{|c|}{ Work shifts during COVID-19 } \\
\hline & $\begin{array}{l}\text { Pre- } \\
\text { COVID }\end{array}$ & $\begin{array}{l}\text { During } \\
\text { COVID }\end{array}$ & $\begin{array}{l}\text { Difference } \\
\quad(\%)\end{array}$ & $P$ & $\begin{array}{c}\text { Not } \\
\text { applied }\end{array}$ & $\begin{array}{l}\text { Applied for } \\
\text { all of the members }\end{array}$ & $\begin{array}{c}\text { Applied for } \\
\text { specialists only }\end{array}$ & $\begin{array}{l}\text { Applied for } \\
\text { residents only }\end{array}$ & Total \\
\hline 1 & 419 & 378 & $9.79 \%$ & 0.645 & 16 & 21 & 0 & 1 & 38 \\
\hline 2 & 330 & 309 & $6.36 \%$ & 0.096 & 10 & 13 & 2 & 2 & 27 \\
\hline 3 & 587 & 540 & $8.01 \%$ & 0.217 & 20 & 28 & 9 & 3 & 60 \\
\hline 4 & 227 & 203 & $10.57 \%$ & 0.984 & 6 & 11 & 2 & 2 & 21 \\
\hline 5 & 38 & 34 & $10.53 \%$ & 0.677 & 4 & 3 & 1 & 0 & 8 \\
\hline Total & 1,601 & 1,464 & $8.55 \%$ & 0.069 & 56 (36.4\%) & 76 (49.4\%) & $14(9 \%)$ & $8(5.2 \%)$ & $100 \%$ \\
\hline
\end{tabular}

of procedures performed per week in each zone and the corresponding percentage reduction is shown in Figure 4 and described by Table IV.

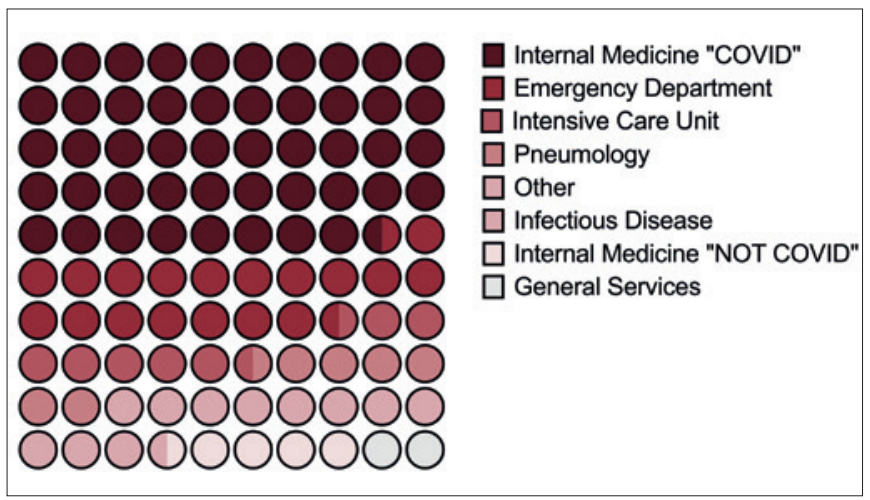

Figure 3. Reallocation of otolaryngology team members to other departments during the pandemic.
Among the different types of surgery, only a small percentage of respondent units declared a reduction in head and neck and emergency surgical procedures $(10.74 \%$ and $3.54 \%$, respectively). On the other hand, the vast majority declared a drastic reduction in endoscopic sinonasal procedures $(98.53 \%)$, paediatric otolaryngology surgery $(97.59 \%)$ and ear surgery $(94.90 \%)$. All elective surgical procedures (100\%) were suspended uniformly across the country (Tab. V).

In this setting, upper airway management and tracheostomy procedures were performed by $42.86 \%$ of units, while the remaining $57.14 \%$ declared that they were not involved in airway management procedures for COVID-19 patients. The vast majority of the units $(70.94 \%)$ declared that the percutaneous tracheostomy technique was predominant over the surgical one in their hospitals. When asked about the timing of tracheostomy procedures the majority of Otolaryngology Units performed this after more than 14 days

Table III. Reallocation of physicians sorted by zone.

\begin{tabular}{|c|c|c|c|c|c|c|c|c|c|}
\hline \multirow[t]{2}{*}{ Zone } & \multicolumn{8}{|c|}{ Reallocation to different departments } & \multirow[b]{2}{*}{ Total } \\
\hline & $\begin{array}{l}\text { Internal } \\
\text { Medicine } \\
\text { COVID }\end{array}$ & $\begin{array}{c}\text { Internal } \\
\text { Medicine } \\
\text { non-COVID }\end{array}$ & $\begin{array}{l}\text { Emergency } \\
\text { Department }\end{array}$ & $\begin{array}{l}\text { Intensive } \\
\text { Care Units }\end{array}$ & $\begin{array}{c}\text { Infectious } \\
\text { Disease Units }\end{array}$ & $\begin{array}{c}\text { Respiratory } \\
\text { Disease Units }\end{array}$ & $\begin{array}{c}\text { Basic } \\
\text { assistance }\end{array}$ & Others & \\
\hline 1 & 25 & 0 & 10 & 6 & 3 & 3 & 1 & 2 & $50(46.7 \%)$ \\
\hline 2 & 10 & 4 & 2 & 2 & 0 & 2 & 1 & 1 & $22(20.5 \%)$ \\
\hline 3 & 11 & 1 & 6 & 1 & 1 & 2 & 0 & 3 & $25(23.4 \%)$ \\
\hline 5 & 1 & 0 & 2 & 0 & 0 & 0 & 0 & 0 & $3(2.9 \%)$ \\
\hline Total & $52(48.6 \%)$ & $5(4.7 \%)$ & $20(18.7 \%)$ & $9(8.4 \%)$ & $5(4.7 \%)$ & $7(6.5 \%)$ & $2(1.8 \%)$ & $7(6.6 \%)$ & $107(100 \%)$ \\
\hline
\end{tabular}


Outpatient visits

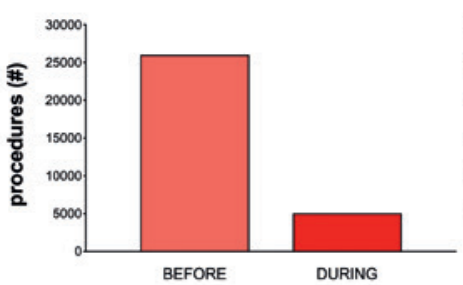

Outpatient surgery

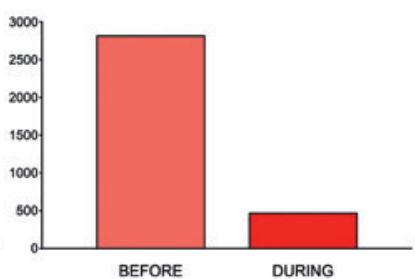

Inpatient surgery

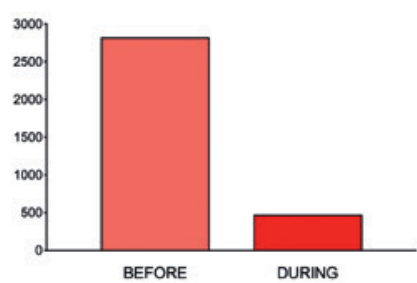

Figure 4. The number of outpatient visits, outpatient surgical procedures, and inpatient surgical procedures comparing pre-COVID and during-COVID variation.

Table IV. Otolaryngology procedures before and during COVID-19 pandemic.

\begin{tabular}{|c|c|c|c|c|c|c|c|c|c|c|c|c|}
\hline \multirow[t]{2}{*}{ Zone } & \multicolumn{9}{|c|}{ Otolaryngology procedures (difference \%) } & \multicolumn{3}{|c|}{ Total (difference \%) } \\
\hline & $\begin{array}{l}\text { Outpatient } \\
\text { visits } \\
\text { before } \\
\text { COVID }\end{array}$ & $\begin{array}{l}\text { Outpatient } \\
\text { visits } \\
\text { during } \\
\text { COVID }\end{array}$ & $P$ & $\begin{array}{c}\text { Outpatient } \\
\text { surgery } \\
\text { before } \\
\text { COVID }\end{array}$ & $\begin{array}{c}\text { Outpatient } \\
\text { surgery } \\
\text { during } \\
\text { COVID }\end{array}$ & $P$ & $\begin{array}{c}\text { Inpatient } \\
\text { surgery } \\
\text { before } \\
\text { COVID }\end{array}$ & $\begin{array}{c}\text { Inpatient } \\
\text { surgery } \\
\text { during } \\
\text { COVID }\end{array}$ & $P$ & $\begin{array}{c}\text { Procedures } \\
\text { before } \\
\text { COVID }\end{array}$ & $\begin{array}{l}\text { Procedures } \\
\text { during } \\
\text { COVID }\end{array}$ & $P$ \\
\hline 1 & 7,702 & $\begin{array}{c}1,341 \\
(82.6 \%)\end{array}$ & $<0.0001$ & 375 & $34(90.9 \%)$ & $<0.0001$ & 841 & $\begin{array}{c}123 \\
(85.4 \%)\end{array}$ & $<0.0001$ & 8,918 & $\begin{array}{c}1,498 \\
(83.2 \%)\end{array}$ & $<0.0001$ \\
\hline 2 & 5,912 & $\begin{array}{c}1,272 \\
(78.5 \%)\end{array}$ & $<0.0001$ & 303 & $31(89.8 \%)$ & $<0.0001$ & 573 & $\begin{array}{c}111 \\
(80.6 \%)\end{array}$ & $<0.0001$ & 6,788 & $\begin{array}{c}1,414 \\
(79.2 \%)\end{array}$ & $<0.0001$ \\
\hline 3 & 8,470 & $\begin{array}{c}1,734 \\
(79.5 \%)\end{array}$ & $<0.0001$ & 506 & $42(91.7 \%)$ & $<0.0001$ & 1,011 & $\begin{array}{c}164 \\
(83.8 \%)\end{array}$ & $<0.0001$ & 9,987 & $\begin{array}{c}1,940 \\
(80.6 \%)\end{array}$ & $<0.0001$ \\
\hline 4 & 3,147 & $\begin{array}{c}620 \\
(80.3 \%)\end{array}$ & $<0.0001$ & 192 & $33(82.8 \%)$ & 0.0013 & 317 & $\begin{array}{c}69 \\
(78.2 \%)\end{array}$ & $<0.0001$ & 3,656 & $\begin{array}{c}722 \\
(80.2 \%)\end{array}$ & 0.0002 \\
\hline 5 & 805 & $\begin{array}{c}100 \\
(87.6 \%)\end{array}$ & 0.0006 & 61 & $5(91.8 \%)$ & 0.081 & 81 & $\begin{array}{c}5 \\
(93.8 \%)\end{array}$ & 0.003 & 947 & $\begin{array}{c}110 \\
(88.4 \%)\end{array}$ & 0.0203 \\
\hline Total & 26,036 & $\begin{array}{c}5,067 \\
(80.5 \%)\end{array}$ & $<0.0001$ & 1,437 & $\begin{array}{c}145 \\
(89.9 \%)\end{array}$ & $<0.0001$ & 2,823 & $\begin{array}{c}472 \\
(83.3 \%)\end{array}$ & $<0.0001$ & 30,296 & $\begin{array}{c}5,684 \\
(81.2 \%)\end{array}$ & $<0.0001$ \\
\hline
\end{tabular}

Table V. Percentage of variation in different types of surgical procedures during the COVID-period in comparison to the pre-COVID period.

\begin{tabular}{lcccccc} 
Period & $\begin{array}{c}\text { Head and neck oncology } \\
\text { surgery }\end{array}$ & $\begin{array}{c}\text { Emergency } \\
\text { procedures }\end{array}$ & $\begin{array}{c}\text { Sinonasal } \\
\text { surgery }\end{array}$ & $\begin{array}{c}\text { Pediatric otolaryngology } \\
\text { surgery }\end{array}$ & $\begin{array}{c}\text { Ear } \\
\text { surgery }\end{array}$ & $\begin{array}{c}\text { Basic otolaryngology } \\
\text { surgery }\end{array}$ \\
Pre-COVID & 121 & 113 & 136 & 83 & 98 & 141 \\
During COVID & 108 & 109 & 2 & 2 & 5 & 0 \\
$\begin{array}{l}\text { Percentage } \\
\text { reduction (\%) }\end{array}$ & $10.74 \%$ & $3.54 \%$ & $98.53 \%$ & $97.59 \%$ & $94.90 \%$ & $100 \%$ \\
\hline
\end{tabular}

of endotracheal intubation (38.5\%), followed by 11-14 days (27.7\%), 7-10 days (26.1\%) and 3-6 days (7.7\%) (Fig. 5).

\section{COVID-19 screening procedures for patients}

and healthcare workers

In total, $35.71 \%$ of the respondent units declared that a HUB hospital was identified in their region to treat nonCOVID-19 patients. In detail, $68.42 \%$ of HUBs were located in zone 1 , while zones 2,3 and 4 declared significantly smaller percentages in their regions $(22.22 \%, 33.33 \%$ and $4.76 \%$, respectively). Interestingly, zone 5 recorded the highest percentage of HUBs (75\%), although this data may be biased by the low number of respondents from this zone. The majority of the units (72.73\%) declared that COVID-19 screening procedures were performed for both patients and healthcare workers, and all of the departments performed screening procedures for inpatients scheduled for surgery. About $20 \%$ of otolaryngology specialists in the respondent units tested positive for COVID-19 screening tests; the highest percentages of cases were recorded in zones 1 and 2 (34.21\% and $29.63 \%$, respectively).

\section{Discussion}

Since the outbreak of the COVID-19 pandemic, the Italian National Healthcare System abruptly reduced elective services to redirect resources to the units most affected by the pandemic. This has translated into a significant 


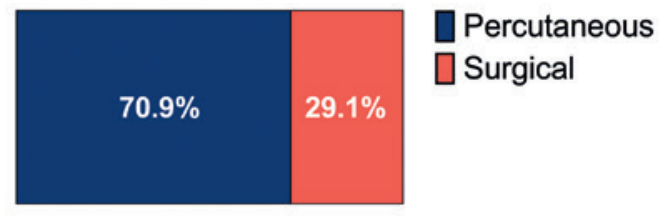

A

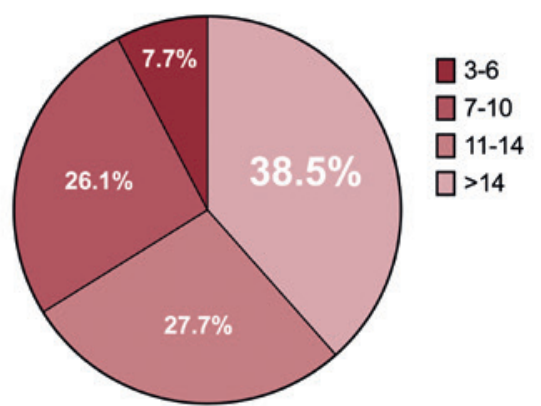

B

Figure 5. (A) surgical and percutaneous tracheostomies; and (B) timing of surgical tracheostomies (days after intubation).

reorganisation of the system which required immediate efforts by all workers throughout the country.

The results of this study confirm that clinical and surgical activities radically changed in Otolaryngology Units across the country. According to the responses to our questionnaire, more than one-fifth $(22 \%)$ of the units were converted or temporary closed, with a progressive and significant reduction according to the zone passing from $39.5 \%$ in zone 1 , to $18.5 \%$ in zone $2,15 \%$ in zone $3,14 \%$ in zone 4 and $25 \%$ in zone 5 .

The consequent marked reduction in outpatient and surgical services per week $(81.24 \%)$ confirms that a significant response to the crisis was provided by Otolaryngology Units; however, this also meant a reduction of nearly 80,000 outpatient visits and almost 10,000 surgical procedures per month. This might have dangerous consequences for the health status of the population and a difficult-to-manage workload in the near future ${ }^{10,11}$.

The activities that were guaranteed during the pandemic were oncology and emergency procedures. In this scenario, it would be fair to assume an increase in overall numbers of these procedures. Nonetheless, the results revealed that even these procedures decreased by nearly $10 \%$ across the country. The reduction of emergency procedures may be explained by the total lockdown that kept the majority of people at home, thus reducing risk factors for otolaryngology emergencies (abscess, bleeding, nasal bone fractures, laryngeal oedema). On the other hand, head and neck cancer cannot be influenced by the lockdown, and some recent articles suggest continuing treating cancer as before but including some safety measures for healthcare workers and patients ${ }^{12-14}$. The reduction observed may be due to the reduced number of beds and personnel in Otolaryngology Units, and might result in more advancedstage oncology cases in the near future.

Despite the five zones identified according to the total number of COVID-19 cases, a homogenous distribution of changes was recorded with a superimposable percentage reduction in staff members. On the other hand, specialist reallocations to other units were mainly recorded in zone 1, demonstrating the greater reorganisation made in the Lombardy and Emilia-Romagna regions ${ }^{15}$.

COVID-19 cases are not distributed homogenously in Italy, therefore a different rate of activity change was expected in Otolaryngology Units across the country. Instead, we did not notice relevant differences in reductions in outpatient evaluations and surgical cases among units in different regions. This shows a great sense of responsibility by the Italian National Healthcare System, which stopped elective activities even in less affected areas.

Tracheostomy is a common procedure for patients admitted to ICUs with acute respiratory distress and with difficult weaning. During the pandemic, many countries published their own guidelines, including the Italian Society of Otolaryngology and Head \& Neck Surgery (SIOeChCF) ${ }^{16}$. Nonetheless, guidelines about timing and technical procedures for tracheostomy are still lacking. Indications and experiences have been published by Italian groups ${ }^{17,18}$, but many questions remain about which technique should be preferred (surgical or percutaneous) and the correct timing to perform tracheostomies in COVID-19 patients. Experience gained from previous severe acute respiratory syndrome coronaviruses (SARS-CoV and MERS-CoV) and from SARS-CoV-2 demonstrated that nurses and physicians who deal with infected patients are at high risk of infection; among physicians, otolaryngologists have been identified as having the highest risk of contracting COVID-19 ${ }^{19}$. Tracheostomy has been demonstrated not to change the course of the disease and is among the most dangerous procedures for surgeons. For these reasons, many authors suggest performing tracheostomy after a longer intubation time. So far, the surgical technique seems to be safer compared with the percutaneous approach since airway opening is short and controlled with the cuffed tube placed caudally to the trachea 
opening. Some modifications to the well-known percutaneous techniques have been proposed to minimise the risk related to COVID-19 infection ${ }^{20}$. These uncertainties are reflected in Figure 5, where differences in terms of technique and postintubation day are revealed. Another consideration is related to the high volume of patients admitted to ICUs in some hospitals during the first month of pandemic spread; in this setting, an elevated number of tracheostomies was motivated by the necessity for rapid weaning and transfer of patients to sub-intensive care units.

This Italian nationwide study showed that otolaryngologists have a high risk of contracting SARS-CoV-2. According to our data, more than $20 \%$ of Otolaryngology Units have had physicians with positive nasal swabs; this percentage was as high as $34 \%$ in the more severely affected regions and some Italian otolaryngologists have died.

\section{Conclusions}

Since the outbreak of COVID-19 in Lombardy and the following WHO declaration of a global pandemic, the Italian National Healthcare System has struggled to cope with the unpredictable load of affected patients. Otolaryngology Units have been involved in treating patients who need tracheostomy and guaranteeing diagnosis and treatment for oncology and emergency patients. This nationwide study showed how prominently phase 1 of the pandemic changed the organisation and activity of Otolaryngology Units across the country. Italy is now starting phase 2 with many questions on the strategies to adopt in the near future to treat patients and protect healthcare personnel ${ }^{21}$.

\section{Acknowledgements}

We heartily thank all of the personnel of the Head and Neck and Otorhinolaryngology Units who have responded to the survey promptly and generously, and we thank our colleagues across the country for their brave commitment during this unexpected crisis.

A special acknowledgement is due to Professor Mario Bussi, President of the Italian Society of Otolaryngology and Head \& Neck Surgery (SIOeChCF), who gave us his trust and support, and helped to gain widespread consent and cooperation with this investigation.

\section{References}

1 Wu F, Zhao S, Yu B, et al. A new coronavirus associated with human respiratory disease in China. Nature 2020;579:265-9. https://doi. org/10.1038/s41586-020-2008-3

2 Horowitz J. Italy's health care system groans under coronavirus - a warning to the world. New York Times 2020. https://www.nytimes. com/2020/03/12/world/europe/12italy-coronavirus-health-care.html
https://COVID19.who.int

4 WHO. Virtual press conference on COVID-19. March 11, 2020. https://www.who.int/docs/default-source/coronaviruse/transcripts/ who-audio-emergencies-coronavirus-press-conference-full-and-final-11mar2020.pdf?sfvrsn=cb432bb3_2

5 Zangrillo A, Beretta L, Silvani P, et al. Fast reshaping of intensive care unit facilities in a large metropolitan hospital in Milan, Italy: facing the COVID-19 pandemic emergency. Crit Care Resusc 2020;22:91-4.

6 Grasselli G, Pesenti A, Cecconi M. Critical care utilization for the COVID-19 outbreak in Lombardy, Italy: early experience and forecast during an emergency response. JAMA 2020;323:1545-6. https:// doi.org/10.1001/jama.2020.4031

7 Cascella M, Rajnik M, Cuomo A, et al. Features, evaluation and treatment coronavirus (COVID-19). [Updated 2020 Aug 10]. In: StatPearls [Internet]. Treasure Island (FL): StatPearls Publishing; 2020 Jan-. Available from: https://www.ncbi.nlm.nih.gov/books/NBK554776/?elqTrackI $\mathrm{d}=\mathrm{acb} 127 \mathrm{f} 200 \mathrm{~d} 54529 \mathrm{bf} 1 \mathrm{a} 65898 \mathrm{f} 737 \mathrm{ab} 7$ \&elqaid $=3961$ \&elqat $=2$

8 Ralli M, Greco A, de Vincentiis M. The effects of the COVID-19/ SARS-CoV-2 Pandemic outbreak on otolaryngology activity in Italy. Ear Nose Throat J 2020:145561320923893. https://doi. org/10.1177/0145561320923893

9 https://www.epicentro.iss.it/coronavirus/bollettino/Bollettino-sorveglianza-integrata-COVID-19_16-aprile-2020.pdf

$10 \mathrm{http}: / / \mathrm{www}$.governo.it/it/faq-fasedue

11 Xu K, Lai XQ, Liu Z. Suggestions for prevention of 2019 novel coronavirus infection in otolaryngology head and neck surgery medical staff. Zhonghua Er Bi Yan Hou Tou Jing Wai Ke Za Zhi 2020;55:E001. https://doi.org/10.3760/cma.j.issn.1673-0860.2020.0001

12 Chaves ALF, Castro AF, Marta GN, et al. Emergency changes in international guidelines on treatment for head and neck cancer patients during the COVID-19 pandemic. Oral Oncol 2020;107:104734. https://doi.org/10.1016/j.oraloncology.2020.104734

13 Crosby DL, Sharma A. Evidence-Based Guidelines for management of head and neck mucosal malignancies during the COVID-19 pandemic. Otolaryngol Head Neck Surg 2020;163:16-24. https://doi. org/10.1177/0194599820923623

14 Ansarin M. Surgical management of head and neck tumours during the SARS-CoV (Covid-19) pandemic. Acta Otorhinolaryngol Ital 2020;40:87-9. https://doi.org/10.14639/0392-100X-N0783

15 Saibene AM, Allevi F, Biglioli F, et al. Role and management of a Head and Neck Department during the COVID-19 outbreak in Lombardy. Otolaryngol Head Neck Surg 2020;194599820917914. https:// doi.org/10.1177/0194599820917914

16 SIOeCHF. La tracheostomia in pazienti affetti da COVID 19. https:// www.sioechcf.it/wp-content/uploads/2020/03/

17 Mattioli F, Fermi M, Ghirelli M, et al. Tracheostomy in the COVID-19 pandemic. Eur Arch Otorhinolaryngol 2020;277:2133-5. https://doi. org/10.1007/s00405-020-05982-0

18 Pichi B, Mazzola F, Bonsembiante A, et al. CORONA-steps for tracheotomy in COVID-19 patients: a staff-safe method for airway management. Oral Oncol 2020;105:104682. https://doi.org/10.1016/j. oraloncology.2020.104682

19 Shiba T, Ghazizadeh S, Chhetri D, et al. Tracheostomy considerations during the COVID-19 pandemic. OTO Open 2020;4:2473974X20922528. https://doi.org/10.1177/2473974X20922528

20 Ranganath NK, Malas J, Phillips KG, et al. Single and double lung transplantation have equivalent survival for idiopathic pulmonary fibrosis. Ann Thorac Surg 2020;109:211-7. https://doi.org/10.1016/j. athoracsur.2019.06.090

21 SIOeCHF. Piano strategico per la gestione del paziente orl durante il periodo di transizione a seguito della pandemia covid 19. https:// www.sioechf.it 